\title{
Comparison of 'Excision and Primary Repair' with 'Bascom's Technique' in the Surgical Treatment of Pilonidal Sinus
}

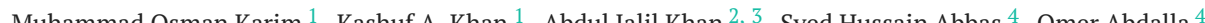
, Muhammad Imran Aslam ${ }^{5}$

1. General Surgery, Royal Shrewsbury and Telford Hospital National Health Service (NHS) Trust, Shrewsbury, GBR 2. Family Medicine, Khyber Medical University, Peshawar, PAK 3. General Practice, National Health Service (NHS), Bolton, GBR 4. General Surgery, Buckinghamshire Healthcare NHS Trust, Wycombe Hospital, High Wycombe, GBR 5. General Surgery, Warwick Hospital, Warwick, GBR

Corresponding author: Kashuf A. Khan, kakhan.89@gmail.com

\section{Abstract}

\section{Introduction}

The management of the chronic pilonidal disease is variable and the principles of treatment are aimed to eradicate the sinus tract, promote wound healing, prevent disease recurrence, and improve the quality of life of the patient. This study aims to compare the effectiveness of excision and primary closure, and Bascom's technique in the management of pilonidal sinus disease.

\section{Methods}

The study was performed at a tertiary hospital from April to October 2011. All patients with chronic pilonidal sinus were included in the study $(\mathrm{n}=60)$ and randomly allocated into Group A - undergoing excision and primary closure $(n=30)$ and Group B - undergoing Bascom's repair. Comparative outcomes of interest were duration of hospital admission, post-operative pain, wound infection, wound-healing and disease recurrence.

\section{Results}

The mean age of presentation was $24.18 \pm 5.6$ years. A higher number of patients in Group A were discharged within 24 hours compared to Group B $(p=0.001)$. Group B had significantly less post-operative pain by the first postoperative week ( $p=0.049)$. Group B had lower infection rates with clean wounds observed in 28 (93.3\%) patients compared to $23(76.7 \%)$ in Group A by the first postoperative week ( $p=0.07)$. Recurrence rate during 12-week follow-up was observed in one (3.3\%) patient in Group B, and five (16.7\%) in Group A $(\mathrm{p}=0.085)$.

Received 03/06/2020

Review began 03/13/2020 Review ended 03/16/2020 Published 03/20/2020

(c) Copyright 2020 Karim et al. This is an open access article distributed under the terms of the Creative Commons Attribution License CC-BY 4.0., which permits unrestricted use, distribution, and reproduction in any medium, provided the original author and source are credited.

\section{Conclusions}

Patients who underwent Bascom's operation had less postoperative pain, lower infection rates and disease recurrence, and better wound healing. Therefore, in our patient cohort, we conclude Bascom's repair appears to be superior to primary excision and repair in reducing patient morbidity.

Categories: General Surgery

Keywords: pilonidal sinus, excision \& primary repair, bascom's repair

\section{Introduction}

Pilonidal sinus disease is characterized by an epithelial tract situated in the skin of the natal cleft, a short distance behind the anus and generally contains hair follicles [1]. It poses a considerable amount of morbidity and additional healthcare costs in young adults due to discomfort, time off work and particularly when complications such as abscess formation or a draining sinus tract ensue $[2,3]$. The incidence is 10 times more common in males due to their hirsute nature and affects adults in their second or third decade of life. Those of Caucasian origin are more likely to suffer from Pilonidal sinus disease than those of African origin due to different hair characteristics and growth patterns [4]. Pilonidal sinus disease is extremely uncommon both before puberty and as well as after the age of 40 years. [5]

No current treatment method satisfies all the requirements for the management of the chronic pilonidal disease. However, the principles of treatment are aimed to eradicate the sinus tract, promote wound healing of overlying skin and minimize disease recurrence as well as patient morbidity [6]. Management techniques used in treating pilonidal sinus disease include phenol injection with or without local excision of the sinus, incision and drainage of the pilonidal abscess, excision and healing by secondary intention, excision and primary closure, excision and reconstructive flaps such as Karydakis procedure and Bascom's technique [7, 
Overall, the two commonly used techniques for the treatment of pilonidal sinus disease include excision and primary closure and Bascom's operation. In excision and primary closure, all the sinus tracts (midline as well as lateral) are excised by an elliptical incision around the sinuses followed by the closure of the wound primarily. This can be done with or without a drain. The closure of the wound is more cosmetically acceptable for some patients and is associated with shorter healing time and this reduced time off work [10]. However, Bascom's operation involves incision, drainage and curettage of a chronic abscess through a lateral incision. Additionally, the excision of midline pits with only a minimal amount of surrounding tissue is performed [12]. The lateral wound is then left open and the midline incisions are closed [8]. There are several advantages of Bascom's technique compared to other procedures including low recurrence rate, minimal morbidity, suitability for day surgery and considerable financial savings [12]. We, therefore, aimed to compare the effectiveness of excision and primary closure, and Bascom's technique in the treatment of pilonidal sinus disease. The main outcomes assessed included duration of hospital admission, postoperative pain, wound infection, wound-healing and disease recurrence.

\section{Materials And Methods}

The study is based on an interventional quasi-experimental design with non-probability prospective sampling and was conducted from April 2011 to October 2011 at The Jinnah Teaching Hospital, Lahore, Pakistan. The study was registered with the institution and with the Research Registry under, "researchregistry2154" and received the necessary institutional approval.

All patients with a clinical diagnosis of chronic pilonidal sinus disease were included in the study. The criterion for exclusion included the site of the pilonidal sinus disease other than midline coccyx, patients with acute exacerbation of sinus disease (abscess formation) and concurrent medical problems, patients unfit for anesthesia, uncontrolled diabetes mellitus and recurrent pilonidal sinus disease. A total of 60 patients who met the inclusion criteria were selected from the outpatient department and included in the study. They were randomly allocated equally into two groups with the assistance of SPSS random number generator. Group A consisted of 30 patients who underwent excision and primary closure, and Group B consisted of 30 patients who underwent Bascom's repair. All patients included in the study underwent preoperative assessment with baseline investigation and were subsequently consented and booked for an elective operation with prophylactic antibiotics given on the day. The operative procedures were performed by the consultants. Clear post-operative instructions were given to every patient regarding daily dressing of the wound, sitz bath and time for stitches removal. All patients were followed-up at one week, three weeks and 12 weeks post-operatively with outcome data collected on a standardized proforma.

The collected data was analyzed using SPSS software. The primary outcomes including duration of admission, post-operative pain, wound healing and recurrence were presented as mean, standard deviations, frequency percentages. The differences between the two groups were compared using the chisquare test and $\mathrm{p}$-value $<0.05$ was considered statistically significant.

\section{Results}

Out of the 60 patients with a diagnosis of pilonidal sinus included in study 55 (91.7\%) were male and five (8.3\%) were female. The mean age of presentation was $24.18 \pm 5.6$, the median was 23.50 and the range was 14-40 years. The majority of patients 43 (71.7\%) were aged between 20 - 30 years at the time of diagnosis (Table 1). The occupation of all the patients was taken into account. The majority of 47 (78.4\%) patients had prolonged sitting and sedentary jobs. Nineteen (31.7\%) were students, 12 (20\%) were drivers and 16 (26.7\%) were shopkeepers. However, only 13 (21.6\%) patients had other non-sedentary professions.

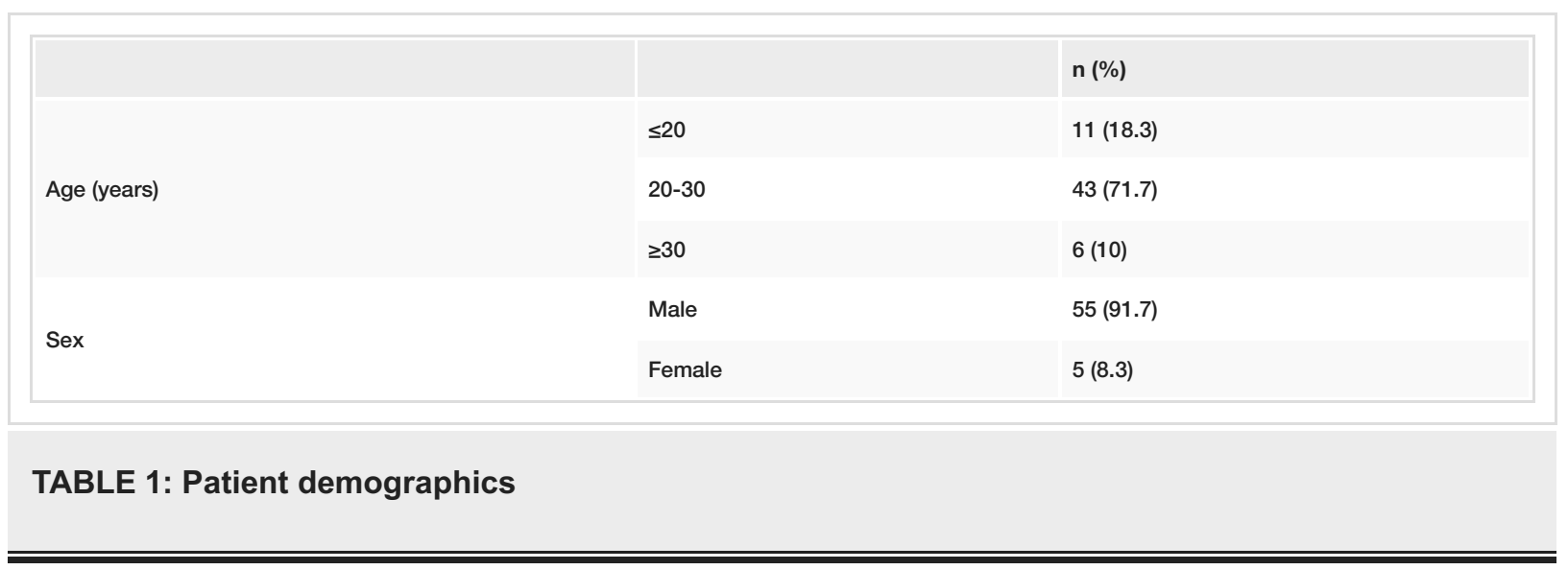

All the patients were discharged providing that there were no immediate complications, wound review was 


\section{Cureus}

satisfactory and pain responded to simple analgesia. In Group A, 21 (70\%) patients were discharged within 24 hours, and nine (30\%) patients were discharged within 48 hours. In Group B, 11 (36.7\%) were discharged within 24 hours and 19 (63.3\%) patients were discharged within 48 hours. The chi-square value was 6.696 and $p$-value $=0.010$. All the patients were followed-up at one-week post-operatively to assess pain. In Group A, 15 (50\%) patients reported no pain, 12 (40\%) reported moderate pain and only three (10\%) expressed severe pain. In Group B, 23 (76.7\%) patients reported no pain; and moderate pain was experienced in only seven (23.3\%) cases. No patient in Group B reported severe pain at one week post-operatively. The chisquare value was 6 and $\mathrm{p}$-value $=0.049$. Surgical wounds were also examined at one-week post-operatively for signs of infection. In Group A, 23 (76.7\%) patients had clean wounds and seven (23.3\%) patients were found with infected wounds. In Group B, 28 (93.3\%) patients had clean wounds and two (6.7\%) patients had signs of wound infection. The chi-square value was 3.268 and $p$-value $=0.070$. At the three-week follow-up wounds were reviewed to assess for healing. In Group A, 24 (80\%) patients had healed wounds and 6 (20\%) patients had partially healed wounds. In Group B, five (16.7\%) patients had completely healed wounds and 24 (80\%) patients showed signs of partial wound healing. There was only one (3.3\%) patient whose wound had not healed completely at three weeks postoperatively. Chi-Square value was 24.248 and p-value = 0.00001. Additionally, wounds were further assessed for signs of infection. In Group A, 25 (83.3\%) patients had with clean wounds and five (16.7\%) patients were found with infected wounds. In Group B, 29 (96.7\%) patients had clean wounds and only one (3.3\%) patient had signs of infection. The chi-square value was 2.963 and $p$-value $=0.085$. All the patients were followed-up after 12 weeks post-operatively to assess for disease recurrence. In Group A, five (16.7\%) patients were found to have the recurrent disease compared to only one (3.3\%) patient in Group B. The chi-square value was 2.963 and p-value $=0.085$ (Table 2).

\begin{tabular}{|c|c|c|c|c|c|}
\hline \multicolumn{2}{|l|}{ Primary Outcomes } & \multicolumn{3}{|c|}{ Outcome Variables n (\%) } & P Value \\
\hline \multirow{3}{*}{ Duration of Admission } & & $0-24$ hours & & 24-48 hours & \\
\hline & Group A & $21 / 30(70)$ & & $9 / 30(30)$ & \multirow{3}{*}{0.001} \\
\hline & Group B & $11 / 30(36.7)$ & & $19 / 30(63.3)$ & \\
\hline \multirow{3}{*}{ Pain (one week) } & & No Pain & Moderate & Severe & \\
\hline & Group A & $15 / 30(50)$ & $12 / 30(40)$ & $3 / 30(30)$ & \multirow{2}{*}{0.049} \\
\hline & Group B & $3 / 30(30)$ & $3 / 30(30)$ & $3 / 30(30)$ & \\
\hline \multirow{3}{*}{ Wound (one week) } & & Clean & & Infected & \\
\hline & Group A & 23/30 (76.7) & & 7/30 (23.3) & \multirow{3}{*}{0.07} \\
\hline & Group B & $28 / 30$ (93.3) & & 2/30 (93.3) & \\
\hline \multirow{3}{*}{ Healing (three weeks) } & & Not healed & Partially & Healed & \\
\hline & Group A & $0 / 30(0)$ & 6/30 (20) & 24/30 (80) & \multirow{2}{*}{0.00001} \\
\hline & Group B & 1/30 (3.3) & $24 / 30(80)$ & 5/30 (16.7) & \\
\hline \multirow{3}{*}{ Wound (three weeks) } & & Clean & & Infected & \\
\hline & Group A & 25/30 (83.3) & & 5/30 (16.7) & \multirow{3}{*}{0.085} \\
\hline & Group B & $39 / 30(96.7)$ & & $1 / 30(3.3)$ & \\
\hline \multirow{3}{*}{ Recurrence (12 weeks) } & & Present & & Absent & \\
\hline & Group A & $5 / 30(1.7)$ & & 25/30 (83.3) & \multirow{2}{*}{0.085} \\
\hline & Group B & $1 / 30(3.3)$ & & 29/30 (96.7) & \\
\hline
\end{tabular}

TABLE 2: Primary Outcomes

\section{Discussion}

Pilonidal sinus disease is an acquired condition usually seen in young adults and is associated with high postoperative morbidity. The onset of pilonidal sinus disease is rare both before puberty as well as after the age of 40 [13]. The mean age of disease presentation was $24.18 \pm 5.6$ years (14-40). However, the majority of patients 43 (71.7\%) presented between the ages of 20-30 years which is consistent with published literature reporting peak incidence in the third decade of life [14]. Additionally, the male to female ratio was 10:1 being consistent with current literature [14, 15]. 
Increased incidence of pilonidal sinus disease was seen during the Second World War amongst US military personnel and was coined as a 'Jeep Bottom' deformity. Similarly, the majority of patients in this study had sedentary occupations and lifestyles. Forty-seven (78.4\%) of patients were either drivers, shopkeepers or students thereby reflecting that prolong sitting may increase the risk of pilonidal sinus disease [16].

All the patients were examined before hospital discharge to ensure there were no immediate complications related to the surgical procedure. In Group A, 21 (70\%) patients compared to 11 (36.7\%) in Group B were discharged within 24 hours of procedure $(p$-value $=0.001)$. Therefore, patients who underwent excision and primary repair were discharged significantly sooner than those who underwent Bascom's operation. No patient in either group required admission greater than 48 hours.

All the patients were followed-up at one week for an assessment of pain and wound review. Patients who underwent Bascom's repair had significantly less post-operative pain with 23 (76.7\%) patients reporting no pain compared to $15(50 \%)$ patients who underwent excision and primary repair ( $\mathrm{p}$-value $=0.049$ ). Additionally, those who underwent Bascom's repair had clean wounds, 28 (93.3\%) compared to 23 (76.7\%) patients who underwent excision and primary closure $(p$-value $=0.070)$. At three-weeks, there were similar results with only one (3.3\%) patient who underwent Bascom's repair showing signs of wound infection compared to $5(16.7 \%)$ patients who underwent excision and primary repair with signs of infection $(\mathrm{p}$-value $=$ 0.085). Although not statistically significant, the results regarding infection rates are similar to existing literature reporting reduced infection rates in Bascom's repair with only 3 (4\%) patients affected [2].

All patients were reviewed 12-weeks post-operatively for signs of disease recurrence. Only one (3.3\%) patient who underwent Bascom's repair compared to five (16.7\%) patients who underwent excision and primary closure presented with recurrence of pilonidal disease $(p$-value $=0.085)$. Although the results were not significant, they are comparable to previous international studies where the recurrence rate after Bascom's technique was $7.3 \%$ with $4.6 \%$ patients requiring further surgery $[2,17]$.

Our study is consistent with findings of a recent meta-analysis advocating the preferred use of Bascom's technique in the treatment of pilonidal sinus disease. In particular, evidence supports Bascom's is associated with better wound healing and reduced morbidity and therefore should replace the conventional treatment of pilonidal sinus disease [18]. However, the limitations of the study include the small cohort size that made it difficult to adequately power the study to detect a difference. These are typical problems associated with small experimental studies and necessitate the need for further multicenter collaboration. This study was a case series and is reported in line with the PROCESS criteria [19].

\section{Conclusions}

In summary, patients who underwent the Bascom's operation had significantly less postoperative pain and better wound healing. Infection rates and disease recurrence was also less frequent in those whom underwent Bascom's repair. Therefore, in our patient cohort, we conclude Bascom's repair appears to be superior to primary excision and repair in reducing patient morbidity.

\section{Additional Information \\ Disclosures}

Human subjects: Consent was obtained by all participants in this study. The Jinnah Teaching Hospital Lahore, Pakistan issued approval JH0532/2010. The study was registered with The Jinnah Teaching Hospital Lahore, Pakistan and received the necessary institutional approval. This study was also registered with Research Registry under identifying number, "researchregistry2154". Animal subjects: All authors have confirmed that this study did not involve animal subjects or tissue. Conflicts of interest: In compliance with the ICMJE uniform disclosure form, all authors declare the following: Payment/services info: All authors have declared that no financial support was received from any organization for the submitted work. Financial relationships: All authors have declared that they have no financial relationships at present or within the previous three years with any organizations that might have an interest in the submitted work. Other relationships: All authors have declared that there are no other relationships or activities that could appear to have influenced the submitted work.

\section{References}

1. Chintapatla S, Safarani N, Kumar S, Haboubi N: Sacrococcygeal pilonidal sinus historical review, pathological insight and surgical options. Tech Coloproctol. 2003, 7:3-8. https://doi.org/10.1007/s101510300001

2. Zorcolo L, Capra F, Seintu F, Casula G: Surgical treatment of pilonidal sinus: results with Bascom's technique. (Article in Italian). Minerva chir. 2004, 59:387-95.

3. Gupta P J: Radiofrequency incision and lay open technique of pilonidal sinus . Kobe J Med Sci. 2003, 49:7582.

4. Khan AS: Management of pilonidal sinus. Pak J Surg. 2002, 7:41-2.

5. Hull TL, Wu J: Pilonidal disease. Surg Clin North Am. 1994, 74:1309-15. https://doi.org/10.1016/S00396109(02)00062-2 
6. Allen-Mersh TG: Pilonidal sinus: finding the right track for treatment. Br J Surg. 1990, 77:123-32. https://doi.org/10.1002/bjs.1800770203

7. Stansby G, Greatorex R: Phenol treatment of pilonidal sinus of the natal crept . Br J Surg. 1989, 76:729-30. 10.1002/bjs.1800760727

8. William NS: The anus and anal canal. Bailey \& Love's Short Practice of Surgery. Russel RCG, Williams NS, Bulstrode CJ (ed): Arnold, London; 2004. 24:1236-71.

9. Shah PS, Abbass QA, Qazi AR, Memon AS: An experience of close versus open surgical method for the treatment of pilonidal disease. Med Channel. 2005, 11:65-7.

10. Choudhry ZA, Akhtar MJ, Rafi Y, et al.: Primary closure after pilonidal sinus excision. Ann K E med Coll. 1997, 2:9-10.

11. Garrido A, Ali R, Ramakrishan V, Stanley PRW: Reconstruction of natal cleft with a perforator based flap . Br J Plast Surg. 2002, 55:671-4. https://doi.org/10.1054/bjps.2002.3943

12. Senapati A, Cripps NPJ, Thompson MR: Bascom's operation in the day surgical management of symptomatic pilonidal sinus. Br J Surg. 2000, 87:1067-70. https://doi.org/10.1046/j.1365-2168.2000.01472.x

13. Sondenaa K, Nesvik I, Anderson E, Søreide JA: Patient characteristics and symptoms in chronic pilonidal sinus disease. Int J Colorectal Dis. 1995, 10:39-42. https://doi.org/10.1007/BF00337585

14. Mann CV, Russell RCG, Williams NS: Pilonidal sinus. Bailey \& Love Short Practice of Surgery. Mateu Cromo, Madrid; 1995. 866-868.

15. Alam NS, Azfaruddin, Rahil RM: Excision with primary closure of pilonidal sinus . Pak J Surg. 2006, 22:82-85.

16. Demirel AH, Koken A, Ongoren AU: Role of obesity, familial tendency \& sedentary occupation in the etiology of pilonidal sinus. Pak J Surg. 2006, 22:187-90.

17. Mosquera DA, Quayle JB: Bascom's operation for pilonidal sinus . J R Soc Med. 1995, 88:45-46.

18. Enriquez-Navascues JM, Emparanza JI, Alkorta M, Placer C: Meta-analysis of randomized controlled trials comparing different techniques with primary closure for chronic pilonidal sinus. Tech Coloproctol. 2014, 18:863-72. doi: 10.1007/s10151-014-1149-5

19. Agha RA, Fowler AJ, Rammohan S, Barai I, Orgill DP, PROCESS group: Preferred reporting of case series in surgery: the PROCESS guidelines. Int J Surg. 2016, 36:319-323. 10.1016/j.ijsu.2016.10.025 